\title{
Pretensioned BFRP reinforced concrete beams: Flexural behaviour and estimation of initial prestress losses
}

\author{
Ana Pavlović ${ }^{1 *}$, Ted Donchev ${ }^{1 *}$, Diana Petkova ${ }^{1}$, Mukesh Limbachiya ${ }^{1}$, and Refad Almuhaisen ${ }^{1}$ \\ ${ }^{l}$ Kingston University London, Department of Civil Engineering, London, UK
}

\begin{abstract}
Fibre Reinforced Polymers (FRP) are becoming a popular reinforcement option for RC elements mainly due to good strength to weight ratio and resistance to corrosion. The main limitation for their wider application is their relatively low Young's modulus, which results in unfavourable serviceability performance, in terms of early development of deflections and cracks. Among others, prestressing has been suggested as one of the possible approaches to addressing this issue, with encouraging results from research conducted so far. This experimental study aimed to explore prestress losses of basalt fibre reinforced polymer (BFRP) reinforced pretensioned concrete beams. Five beams were produced, three of them internally reinforced with $6 \mathrm{~mm}$ diameter BFRP bars, pretensioned to $20 \%, 30 \%$ and $40 \%$ of the ultimate load level of prestress. Additionally, two beams, acting as control samples, were reinforced with unprestressed BFRP and steel bars of same cross-sectional area, respectively. The dimensions of all samples were $125 \times 200 \times 1900 \mathrm{~mm}$. Prestress losses were monitored with the aid of strain gauges attached to the reinforcing bars, as well as load cells. The strain readings were continuously taken during the pretensioning process, from initial application of the prestressing force, during casting and curing of concrete, until releasing of the beams from prestressing devices after curing. Ultimately, all samples were subjected to a quasi-static, load-controlled, four-point bending test until destruction. The results provide the information about the flexural behaviour of pretensioned BFRP reinforced beams, along with insight into some of the initial prestress losses of these elements.
\end{abstract}

\section{Introduction}

Until the last decades of the 20th century, steel reinforcement was exclusively used for internally reinforced concrete structures. With the increasing popularity of Fibre Reinforced Polymers (FRP), they have been considered a viable alternative for steel in certain applications, such as marine structures and bridges, where exposure to aggressive environments can cause corrosion of the steel.

In addition to excellent chloride corrosion resistance, FRPs also have high strength-to-weight ratio, nonferrous and non-conductive nature, which make them suitable for various other structural applications. Nonetheless, they are often characterised as costly, especially in case of Carbon FRPs (CFRP). Hence other fibres, such as glass and, more recently, basalt have been utilised as a more economic substitute for carbon. Glass and Basalt FRPs (BFRP), on the other hand, have a much lower Young's modulus in comparison with CFRP, which results in poor performance as per serviceability limit state (SLS) criteria, with larger deflections at lower levels of loading and intensive development of cracking. To overcome this issue, prestressing of the FRP reinforcement has been proposed as a possible solution. This paper discusses experimental results of a study of pretensioned BFRP reinforced concrete beams.

\section{Background}

Prestressing of FRP materials has been a topic of research since the turn of the last century. A notable contribution was made in 1998 through the construction of the Taylor bridge in Canada. One tenth of the 40 support girders were produced with prestressed CFRP, and the deck has also been reinforced with GFRP bars [1].

An early contribution was made by Pearson and Donchev [2], who conducted experiments with posttensioned BFRP reinforced concrete beams with and without grouting of the prestressing bars. The results indicated that the effect of the prestressing is much higher in the case of grouting of the bars and with the highest level of prestress (75\%), resulting in an increase of the applied external load at the SLS limit by $70 \%$.

Thorhallson and Jonsson [3] conducted a similar study with BFRP prestressed members, with no shear reinforcement. This study did not observe increase in capacity with prestressing of the member; however, it did agree with the conclusion that the deformation performance of pretensioned (PT) samples was improved in terms of lower deflections.

Furthermore, Crossett et al. [4] conducted research on self-compacting concrete (SCC) beams prestressed with $12 \mathrm{~mm}$ diameter BFRP bars. The experimental investigation showed that prestressing of BFRP tendons resulted in increase in capacity over non-prestressed 
samples, as well as improved serviceability performance, both in terms of more limited deflections and reduced cracking. The increase of ultimate capacity was attributed to the higher reinforcing ratio and concrete crushing failure mode noted for all BFRP reinforced beams.

Encouraging results were also published by Mirshekari et al. [5]. The study was conducted on four beams of the same dimensions, with different levels of prestressing; namely, $0 \%, 20 \%, 30 \%$ and $40 \%$ of the ultimate tensile capacity of the BFRP bars. Additionally, a steel reinforced unprestressed beam was also produced as a control sample. The beams were otherwise equally reinforced with steel top reinforcement and shear links and submitted to a four-point bending test until failure. The analysis of the results confirmed that prestressing BFRP over $30 \% \mathrm{f}_{\mathrm{tu}}$ improves the serviceability performance of the elements to a level comparable to that of a steel reinforced element. In addition, the authors pointed out that all BFRP reinforced beams demonstrated a higher capacity than the steel reinforced control sample, where increase of the level of prestress attributed for an increase in the capacity as well.

Lago et al. [6] constructed a large scale BFRP prestressed bridge deck and tested it by investigating its flexural behaviour and presenting numerical analysis of the structural member. The results of the study were also positive with regards to structural performance; although, problems with the mechanical anchorage of the bars were identified.

Despite the considerable research conducted on BFRP prestressed elements, the long-term behaviour and prestress losses remain insufficiently investigated. A recent contribution was made by Pavlović et al. [7] who experimentally investigated short and long-term prestress losses of six samples of pretensioned BFRP reinforced beams over a period of three months.

This paper presents results of a parallel experimental study conducted at Kingston University London to give a contribution to the knowledge of flexural behaviour and prestress losses of BFRP pretensioned RC beams.

\section{Methodology}

Five samples were produced and tested in the Structures Laboratories at Kingston University London. The samples were concrete beams with a rectangular $125 \times 200 \mathrm{~mm}$ cross section, $1900 \mathrm{~mm}$ long.

The reinforcement cages were constructed with two $6 \mathrm{~mm}$ diameter high-yield steel top reinforcement bars and $6 \mathrm{~mm}$ diameter mild steel shear links with $100 \mathrm{~mm}$ spacing. The pure bending zone, mid $600 \mathrm{~mm}$ of the span, was not reinforced with any shear links. The main (tensile) reinforcement is given in Table 1.
Table 1 Reinforcement specification of samples

\begin{tabular}{|l|l|l|}
\hline $\begin{array}{l}\text { Sample } \\
\text { ID }\end{array}$ & $\begin{array}{l}\text { Main (tensile) } \\
\text { reinforcement }\end{array}$ & $\begin{array}{l}\text { Prestress } \\
\text { force }\end{array}$ \\
\hline S0 & N6 high yield steel & $0 \% \mathrm{f}_{\mathrm{tu}}$ \\
\hline BFRP0 & $\varnothing 6 \mathrm{~mm}$ BFRP RockBar & $0 \% \mathrm{f}_{\mathrm{tu}}$ \\
\hline BFRP20 & $\varnothing 6 \mathrm{~mm}$ BFRP RockBar & $20 \% \mathrm{f}_{\mathrm{tu}}$ \\
\hline BFRP30 & $\varnothing 6 \mathrm{~mm}$ BFRP RockBar & $30 \% \mathrm{f}_{\mathrm{tu}}$ \\
\hline BFRP40 & $\varnothing 6 \mathrm{~mm}$ BFRP RockBar & $40 \% \mathrm{f}_{\mathrm{tu}}$ \\
\hline
\end{tabular}

Additionally, for the three prestressed samples, stainless steel sleeve bonded anchorage was installed on either end of the bars, in accordance with the recommendations given in ACI440R [8], using Webertec EP Epoxy Structural Adhesive. The sleeve was used as a connection between the BFRP bars and steel threaded bars, which were utilised during the prestressing process. The initial prestress force was applied using a manual hydraulic jack on both bottom bars simultaneously and monitored with NovaTech F313 Low Profile Donut 100kN load cells.

After prestressing was completed, all 5 beams were cast using the same batch of $\mathrm{C} 30 / 35$ ready-mix concrete; to verify the strength and class of concrete, standard cubes and cylinders were also prepared. The samples after casting are shown in Fig. 1. The concrete was cured for 28 days in laboratory conditions; ambient temperature, as well as internal concrete temperature were also monitored using thermocouples.

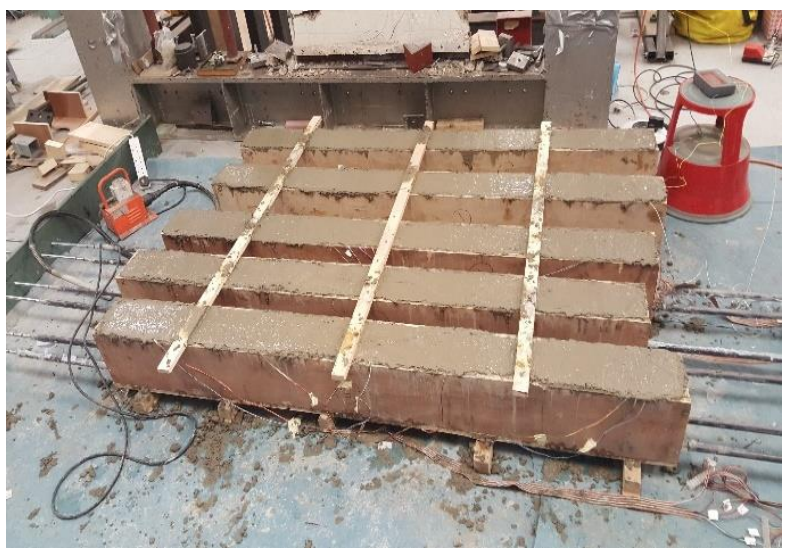

Fig. 1 Samples immediately after casting of concrete

After 28 days curing, the prestress was gradually released from the external anchorage and transferred to fully cured concrete by manually unscrewing the anchor nuts, whilst clamping the anchor sleeves to prevent any torsional effects.

Throughout the application of prestress, casting and curing of concrete, until the release and transfer of prestress, the load in the bars was monitored using NovaTech $100 \mathrm{kN}$ load cells, and strains of the BFRP bars in the midspan and close to supports were monitored using Vishay $120 \pm 0.3 \% \Omega$ foil strain gauges. 
Results were continuously recorded using VPG System 8000 data acquisition system at a $1 \mathrm{~Hz}$ rate.

Following the release of prestress and cutting off sleeve anchors, the beams were subjected to destructive four-point bending tests, over a $1700 \mathrm{~mm}$ span and $600 \mathrm{~mm}$ spacing between point loads. The test was loadcontrolled, at a rate of $2 \mathrm{kN} / 5 \mathrm{~min}$, applied using a hydraulic jack mounted on a reaction frame. During the testing, load was monitored using a load cell, deflections using LVDTs, and strains of reinforcement using strain gauges, and the data was recorded using the VPG System 8000 data acquisition system at $60 \mathrm{~Hz}$ rate. Crack development was manually traced and noted.

\section{Experimental results}

\subsection{Initial strain level monitoring}

The presented results were obtained from strain gauges installed on the BFRP bars at $50 \mathrm{~mm}$ from the edge of the beam. All the gauges showed decrease of strain throughout monitoring. In the initial $24 \mathrm{~h}$ from the application of the external prestress, the decrease was noticeably faster, at an approximate rate from $0.14 \%$ to $0.28 \%$ per hour. This period accounted for the largest total loss of from $3.3 \%$ to $6.7 \%$ of the initially applied strain.

Following the casting of concrete and the described initial period of intense losses, the rate of decrease became much slower, with strain decreasing at approximately less than $0.1 \%$ per day. This rate was maintained at an approximately constant level throughout the curing period, up until the release of the bars from the external anchorage and transfer of the prestressing force to the cured concrete elements.

\subsection{Final Testing}

As described, after transfer of the prestressing force to the cured concrete beams, the samples were subjected to four-point bending test until failure, and the results are described in this section. Fig. 2 shows the load versus deflection graphs of all five tested samples.

As seen on the graph, the steel control sample exhibited a near-linear behaviour until a load of approximately $8 \mathrm{kN}$ was applied, corresponding to the appearance of the first crack. After this, the deflections were developing more rapidly with increase of the load, followed by typical yielding plateau with reaching of the ultimate load of $22.5 \mathrm{kN}$, and the decrease of load after failure.

The behaviour of the BFRP reinforced unprestressed sample was similar until the appearance of the first crack, which also occurred at approximately $8 \mathrm{kN}$ of load. After this point, the development of deflections was much more rapid than for the steel reinforced sample, reaching the ultimate deflection of approximately $60 \mathrm{~mm}$, at the ultimate load of over $40 \mathrm{kN}$.

All the prestressed samples exhibited an increase in stiffness in comparison with the unprestressed BFRP sample. In addition to that, each increase of the level of prestressing resulted in a delay of the point of change of stiffness, which occurred at approximately $14 \mathrm{kN}, 22 \mathrm{kN}$ and $26 \mathrm{kN}$ for BFRP20, BFRP30 and BFRP40 samples respectively. There was no increase in the ultimate load in comparison with BFRP0, with all samples failing after reaching a load of over $40 \mathrm{kN}$. However, the midspan deflection of each prestressed sample was significantly lower compared to BFRP0; reaching maximum values of $42.2 \mathrm{~mm}, 34.4 \mathrm{~mm}$ and $21.4 \mathrm{~mm}$ for BFRP20, BFRP30 and BFRP40 respectively.

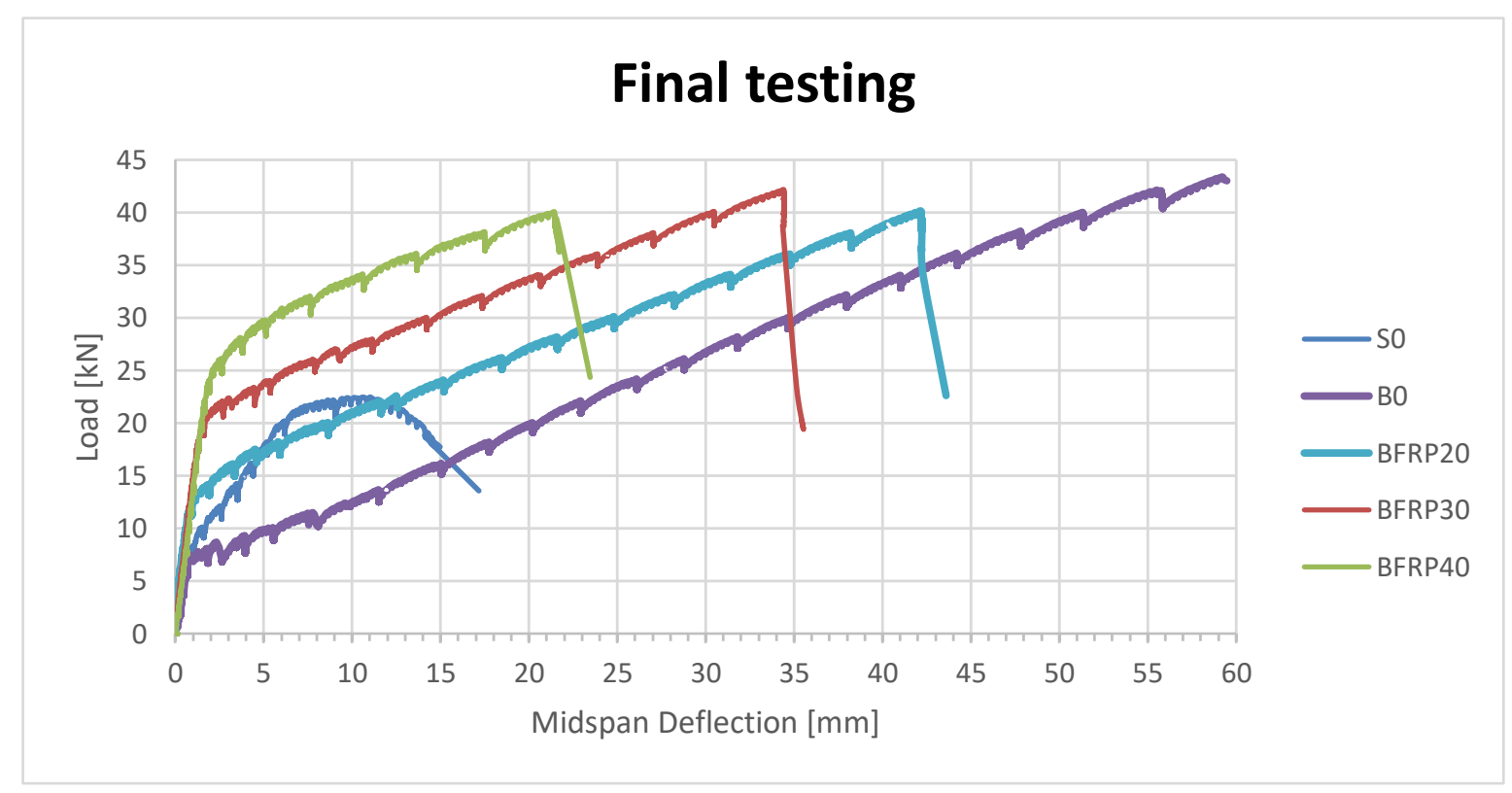

Fig. 2 Four-point bending test results: Load Vs Deflection 

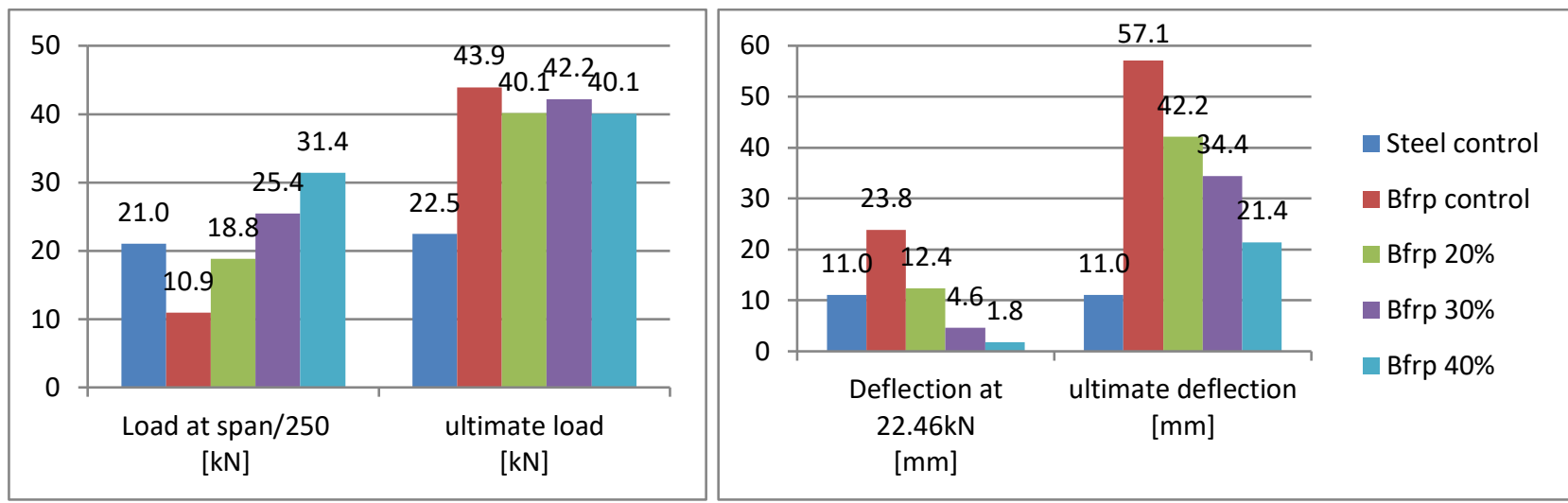

Fig. 3 Summary of ULS and SLS load and deflection results

\section{Discussion}

The summary of the results of the final four-point bending test is given in Fig. 3. The analysis of ultimate load reached during four-point bending test of the beams shows that the increase in load-bearing capacity of BFRP reinforced samples in comparison with the steel reinforced control sample is significant, from around $78 \%$ to $95 \%$ of the ultimate load of S0. It is also worth noting that the prestressed samples did not reach a higher ultimate load than the unprestressed BFRP sample.

On the other hand, the increase of the ultimate deflection of B0 compared to S0 was significant, over $400 \%$. Prestressing of the beams evidently had a beneficial effect on the development of deflections, i.e. with increase of the level of prestressing, the ultimate deflection measured at the midspan decreased.

Moreover, the comparison of load reached for each sample at the serviceability limit state (SLS) criteria of $\operatorname{span} / 250(6.8 \mathrm{~mm})$ [9] also reflects the positive effect of prestressing regarding limiting the deflections. Samples which were prestressed to $30 \%$ and $40 \%$ of the ultimate tensile capacity of the BFRP bars exceeded the performance of the steel reinforced beam, by achieving $21 \%$ and $50 \%$ higher load than S0 at the specified limit, respectively.

In addition, analysis of modes of failure of each sample was also conducted. As shown in Fig. 4 the crack pattern of all beams was that of a flexural failure, with cracks extending at a near-vertical angle, with some approaching a more diagonal angle near the load application points.

The destruction of S0 was characteristic of an underreinforced beam; the sample failed by yielding of tensile reinforcement, which is also evident on the load vs deflection graph (Fig. 2). On the other hand, the destruction of BFRP0 was brittle, with deflections and cracks progressing continually until failure, which occurred by rupture of the BFRP bars. Similarly, the failure of all prestressed samples was distinctively brittle, with little to no prior warning before the failure, which also occurred by rupture of the bars. This was especially pronounced in the case of BFRP30 and BFRP40. For practical applications, this issue could be addressed in several ways, such as the usage of hybrid prestressed/unprestressed reinforcement, structural health monitoring etc. The prestressed samples developed a smaller number of cracks in comparison with BFRP0, with the least number of cracks observed for BFRP40.

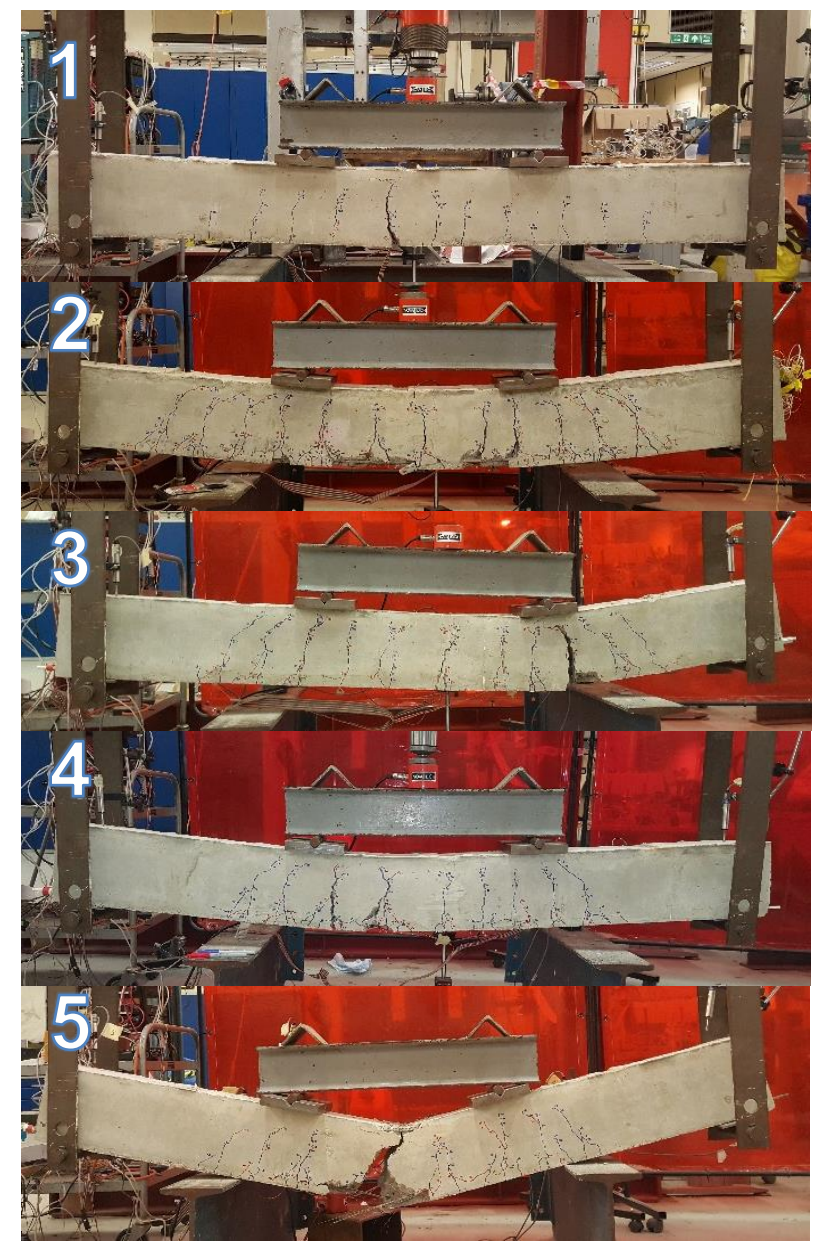

Fig. 4 Photographs of all samples at the end of the four-point bending test ( 1 - S0; 2 - BFRP0; 3 - BFRP20; 4 - BFRP30; 5 - BFRP40)

Additionally, an overview of initial crack load increments is given in Fig. 5. The results show that both the steel and BFRP reinforced unprestressed samples 
had a first visible crack at a load of approximately $8 \mathrm{kN}$. The opening of cracks is related to exceeding of the tensile strength of concrete on the tensile face of the flexural member; therefore, by introduction of a prestressing force, the appearance of cracks was delayed for prestressed samples. Furthermore, the increase of the level of prestress resulted in a further delay of the appearance of the first crack on the bottom of the beams. It should be also noted that all the initial cracks appeared in close proximity to the midspan of the loaded samples.

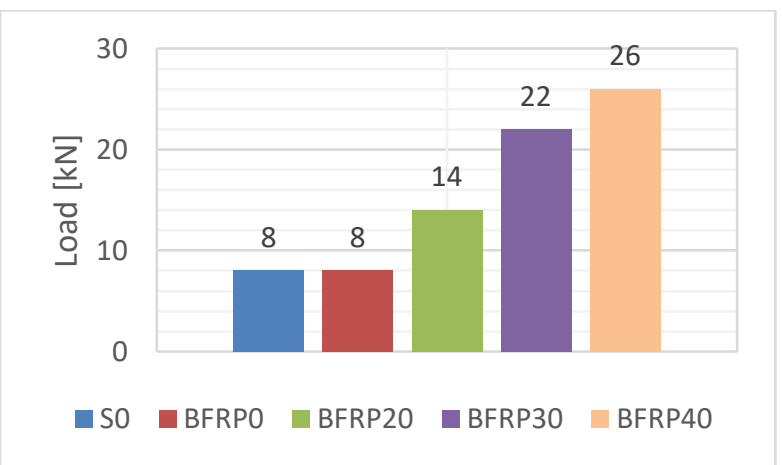

Fig. 5 Load corresponding to initial crack appearance

\section{Conclusions}

Based on continuous monitoring of the initial strain level and subsequent analysis, the following conclusions can be made:

- The fastest rate of decrease of strain, of approximately $0.20 \%$ per hour on average, was observed for the initial period of around $24 \mathrm{~h}$ from the application of the external prestressing force.

- The subsequent period was characterised by a much more gradual continuous decrease of strain, at a rate of around $0.1 \%$ per day.

Additionally, based on the flexural behaviour of five samples tested under four-point bending until destruction, the following can be concluded:

- Prestressing of BFRP reinforced samples with over $30 \%$ of the ultimate tensile capacity of the bars improved the serviceability performance of the beams to a level higher than that of the steel reinforced sample.

- Ultimate deflections of all prestressed samples were reduced in comparison with the unprestressed BFRP sample.

- The initial appearance of cracks on the tensile face of the samples was delayed for the prestressed samples, correspondingly with the level of prestressing applied.

\section{Acknowledgements}

The authors would like to express their gratitude to MagmaTech UK Ltd. for sponsoring the project with RockBar BFRP bars, as well as to the technical staff of the Structures Laboratories at Kingston University London.

\section{References}

[1] Shehata, E. et al. (1999) Taylor Bridge - A Bridge For the 21 st Century. Winnipeg Manitoba, World Wise 99

[2] Pearson, M., Donchev, T. (2013) Experimental Study on the Behaviour of Prestressed Concrete Beams with Internal BFRP Reinforcement. Proceedings of the $11^{\text {th }}$ International Symposium FRPRCS11, Guimaraes, Portugal, June 26-28, 2013

[3] Thorhallsson E.R., and Jonasson, B. (2012) Test of Prestressed Concrete Beams with BFRP tendons. The 6th International Conference on FibreReinforced Polymer (FRP) Composites in Civil Engineering (CICE 2012), 13-15 June 2012, Rome, Italy

[4] Crossett, P., Taylor, S., Robinson, D., Sonebi, M., Garcia-Taengua, E., Deegan, P., and Ferrara, L. (2015) The Flexural Behaviour of SCC Beams Prestressed with BFRP. Proceedings of the $7^{\text {th }}$ Beinnial Conference on Advanced Composites in Construction (ACIC 2015), 09-11 September 2015, Cambridge, UK

[5] Mirshekari, M., Donchev, T., Petkova, D., and Limbachiya, M. (2016) Deformability of Pretensioned PC Beams with BFRP Reinforcement. The 8th International Conference on Fibre-Reinforced Polymer (FRP) Composites in Civil Engineering (CICE 2016), 14-16 December 2016, Hong Kong, China

[6] Lago, B., Taylor, S., Deegan, P., Ferrara, L., Sonebi, M., Crosset, P., and Pattarini, A. (2017) Full-scale testing and numerical analysis of a precast fibre reinforced self-compacting concrete slab pre-stressed with basalt fibre reinforced polymer bars. Composites Part B, 128, pp. 120133

[7] Pavlović, A., Donchev, T., Petkova, D. and Limbachiya, M. (2019). Initial estimate of short and long-term prestress losses of BFRP pretensioned RC beams. Proceedings of the $14^{\text {th }}$ International Symposium FRPRCS14, Belfast, UK, June 4-7, 2019

[8] ACI Committee 440 (2004) 440.3R-04: Guide Test Methods for Fiber-Reinforced Polymers (FRPs) for Reinforcing or Strengthening Concrete Structures. American Concrete Institute, USA

[9] The European Committee for Standardisation (1992) EN 1992-1-1: Eurocode 2: Design of concrete structures - Part 1: General rules and rules for buildings, Section 4.4.3.1 (5) 